\title{
Efficacy of sorafenib in patients with gastrointestinal stromal tumors in the third- or fourth-line treatment: A retrospective multicenter experience
}

\author{
UMUT KEFELI $^{1}$, MUSTAFA BENEKLI ${ }^{2}$, ALPER SEVINC ${ }^{3}$, RAMAZAN YILDIZ ${ }^{4}$, MUHAMMED ALI KAPLAN $^{5}$, \\ AYDIN CILTAS $^{2}$, OZAN BALAKAN $^{3}$, ABDURRAHMAN ISIKDOGAN $^{5}$, UGUR COSKUN $^{2}$, FAYSAL DANE $^{6}$, \\ HAKAN HARPUTLUOGLU $^{7}$, HALIT KARACA ${ }^{8}$, DOGAN YAZILITAS ${ }^{9}$, AYSE DURNALI ${ }^{10}$, ALI OSMAN KAYA ${ }^{11}$, \\ UMUT DEMIRCI $^{12}$, MAHMUT GUMUS $^{4}$ and SULEYMAN BUYUKBERBER ${ }^{2 *}$
}

\author{
${ }^{1}$ Department of Medical Oncology, Medeniyet University Goztepe Training and Research Hospital, Istanbul; \\ ${ }^{2}$ Department of Medical Oncology, Gazi University Faculty of Medicine, Ankara; ${ }^{3}$ Department of Medical Oncology, \\ Gaziantep University Faculty of Medicine, Gaziantep; ${ }^{4}$ Department of Medical Oncology, Dr. Lutfi Kirdar Kartal Education \\ and Research Hospital, Istanbul; ${ }^{5}$ Department of Medical Oncology, Dicle University Faculty of Medicine, Diyarbakir; \\ ${ }^{6}$ Department of Medical Oncology, Marmara University Faculty of Medicine, Istanbul; ${ }^{7}$ Department of Medical Oncology, \\ Inonu University Faculty of Medicine, Malatya; ${ }^{8}$ Department of Medical Oncology, Erciyes University Faculty of Medicine, \\ Kayseri; ${ }^{9}$ Department of Medical Oncology, Konya Education and Research Hospital, Konya; \\ ${ }^{10}$ Department of Medical Oncology, Dr. A.Y. Ankara Oncology Education and Research Hospital, Ankara; \\ ${ }^{11}$ Department of Medical Oncology, Medicana Bahcelievler Hospital, Istanbul; \\ ${ }^{12}$ Department of Medical Oncology, Ataturk Education and Research Hospital, Ankara, Turkey
}

Received December 23, 2012; Accepted June 5, 2013

DOI: $10.3892 / 01.2013 .1408$

\begin{abstract}
Sorafenib is a multi-targeted tyrosine kinase receptor inhibitor used to treat patients with advanced gastrointestinal stromal tumors (GISTs). The present study evaluated the efficacy and tolerability of sorafenib therapy for patients with GISTs. Between January 2001 and November 2012, 25 patients, from multiple centers, who had received sorafenib as the third- or fourth-line treatment for GISTs were investigated retrospectively. In total, 17 patients were male and eight were female. The median age was 54.0 years (range, 16-82 years). From the patients, 21 received imatinib for longer than six months and four received it for less than six months. The clinical benefit rate of sorafenib was $40.0 \%$. Treatment-related adverse events were reported in $72 \%$ of patients. These adverse events were generally mild to moderate in intensity. The median progression-free survival (PFS) and overall survival (OS) times of the patients who received sorafenib were 7.2 and
\end{abstract}

Correspondence to: Dr Umut Kefeli, Department of Medical Oncology, Medeniyet University Goztepe Training and Research Hospital, Doctor Erkin Street, Kadıköy, Istanbul, Turkey

E-mail: ukefeli@yahoo.com

*On behalf of the Anatolian Society of Medical Oncology (ASMO)

Key words: sorafenib, gastrointestinal stromal tumors, efficacy
15.2 months, respectively. The duration of imatinib usage was an independent prognostic factor for PFS and OS. Sorafenib is an effective treatment in patients with GISTs showing a clinical benefit rate of $40.0 \%$ and an acceptable tolerability.

\section{Introduction}

Gastrointestinal stromal tumors (GISTs) are the most common mesenchymal neoplasms of the gastrointestinal tract and are highly resistant to conventional chemotherapy (1). C-kit (also known as CD117) expression occurs in $~ 95 \%$ of GISTs, thereby enabling differentiation from other mesenchymal spindle-cell neoplasms (2). C-kit is a transmembrane receptor that is activated by binding of the KIT ligand, a stem cell factor. Of all the GISTs, $\sim 85-90 \%$ are associated with gain-of-function KIT gene mutations that lead to the constitutive activation of KIT kinase activity. A significantly smaller proportion (5\%) are associated with analogous gain-of-function mutations in PDGFRA, the gene encoding platelet derived growth factor receptor $\alpha(\mathrm{PDGFR} \alpha) ;<10 \%$ contain no identified receptor tyrosine kinase mutations (3-5). Experience gained from epidemiological studies and active GIST therapeutic trials suggests that the annual incidence of GISTs in the United States is at least 4,000 to 6,000 new cases (roughly seven to 20 cases per million population) per year (6).

Surgical resection remains the mainstay therapy for GISTs, but recurrence is common. The five-year survival rates for GISTs following complete resection range between 40 and 65\% (7-11). Imatinib mesylate selectively inhibits certain protein tyrosine 
kinases; intracellular ABL kinase, chimeric BCR-ABL fusion oncoprotein of chronic myeloid leukemia, the transmembrane receptor KIT and platelet-derived growth factor receptors (PDG-FR) (12-15). Imatinib mesylate has induced a sustained objective response in $>50 \%$ of patients with advanced GISTs in Western and other countries (16-18). However, the response to imatinib therapy is time-limited and secondary resistance to imatinib therapy (following initial stabilization or response) develops in the majority of patients (19).

Sunitinib malate is an oral multi-targeted receptor tyrosine kinase inhibitor that has shown antiangiogenic and antitumor activities in several in vitro and in vivo tumor models (7,20-25). Sunitinib has shown effective activity for patients with GISTs after imatinib failure or intolerance, and has induced a sustained clinical benefit in advanced GISTs (7,18). A number of imatinib-resistant mutations confer cross-resistance to sunitinib. Therefore, various agents, including sorafenib, have been tested as salvage therapy for patients with these resistant GISTs (26). In a prospective multicenter phase II study involving patients with unresectable, KIT-positive GISTs that had progressed under imatinib and sunitinib treatment, 55\% of patients who received sorafenib had stable disease and $13 \%$ had partial responses (27). In a retrospective analysis of 32 patients, sorafenib was shown to be significantly active in patients with metastatic GISTs resistant to imatinib and sunitinib (28).

Based on the limited data, guidelines have included sorafenib as an option for patients who are no longer receiving a clinical benefit from imatinib or sunitinib (29). Therefore, the aim of the present study was to report the results of sorafenib treatment in Turkish GIST patients.

\section{Materials and methods}

Patients and study design. A total of 250 patients with GISTs from ten institutions in Turkey were retrospectively evaluated. All cases of surgically or endoscopically resected GISTs, investigated by the pathology departments of the participating institutions (between January 2001 and November 2012), were reviewed. Of these, the cases of 25 patients who received sorafenib as the third- or fourth-line treatment from eight institutions were selected for evaluation according to the Response Evaluation Criteria in Solid Tumors (RECIST) (30). Follow-up data were obtained from clinical records and histopathology reports. Written informed consent was obtained from all patients. The GISTs were defined as primary spindle cell, epithelioid cell and mixed neoplasms of the tubular GI tract with an overexpression of CD117 and with or without CD34 expression, according to well-established criteria for GIST diagnosis $(31,32)$. Mitoses were counted in 50 high-power fields. Tumor sizes were recorded as the largest diameter in any dimension of the primary tumor and were classified as $<2$, $2-5,5-10$ or $>10 \mathrm{~cm}$. The malignant potential of the GISTs was classified according to the risk categories proposed by Fletcher et al (32). The patient, tumor and treatment variables were recorded. Patient data included age, gender and presentation status. All patients with any metastatic disease were considered to have a metastatic presentation, regardless of whether they had received prior therapy or had also had local recurrence. All tumors were regarded as being histologically malignant.
Statistical analysis. All data were analyzed using SPSS 17.0 software (SPSS Inc., Chicago, IL, USA). Based on the low number of patients, non-parametric tests were selected for the evaluation. Actuarial survival was determined by Kaplan-Meier analysis. Tumor response rates were evaluated as complete response (CR), partial response (PR), stable disease (SD) and progressive disease (PD) according to the RECIST criteria (30). CR, PR and SD were accepted as a response to sorafenib treatment, while PD was accepted as a non-responsive to sorafenib treatment. The duration of imatinib usage was recorded as more or less than six months. Progression free survival (PFS) was defined as no progression after sorafenib use. Overall survival (OS) was defined as survival following the administration of sorafenib and mortality was the endpoint of the study. The associations of patient, tumor and treatment characteristics with outcome were tested by univariate analysis using a log-rank test. A multivariate analysis was performed using the Cox proportional hazards model, and only variables that were deemed statistically significant were included in the final Cox model. Multivariate P-values were used to characterize the independence of these factors. The $95 \%$ confidence interval (CI) was used to quantify the association between survival time and each independent factor. All P-values were two-sided in the tests and $\mathrm{P}<0.05$ was considered to indicate a statistically significant difference.

\section{Results}

Clinical features. Between January 2001 and November 2012, a total of 250 patients with GISTs were evaluated and 25 who had treatment failure with imatinib and other thyrosine-kinases inhibitors were included in the present study. All patients were previously treated with imatinib. Of these, 17 (68.0\%) were male and eight $(32.0 \%)$ were female. The median age was 54.0 years (range, 16-82 years) and the peak age was between 40 and 60 .

Of the GIST patients, $77 \%$ were diagnosed as clinically symptomatic. The most commonly presented symptoms were abdominal pain and non-specific symptoms due to an abdominal mass $(55.5 \%)$. The tumors most commonly originated in the stomach $(20.0 \%)$ and the small intestine $(64.0 \%)$. Histologically, the majority of tumors were predominantly spindle-shaped $(36.0 \%)$ or of mixed type $(36.0 \%)$. All of the tumors were CD117-positive, while $68.0 \%$ were CD34-positive. A total of 17 patients $(68.0 \%)$ presented with metastasis at diagnosis. Among these patients, 11 of the metastasis sites were the liver $(64.7 \%)$, three were the peritoneum $(17.6 \%)$, one was the lung $(5.9 \%)$ and two were other sites $(11.8 \%)$. In total, 21 patients $(84.0 \%)$ received imatinib for longer than six months, while four $(16.0 \%)$ received it for less than six months (Table I).

The majority of the tumors $(72.0 \%)$ were $>10 \mathrm{~cm}$ in size. Based on the size of the primary tumor, the localization and the mitotic index, $24.0 \%$ of the patients were classified as intermediate-risk and $76.0 \%$ as high-risk according to the NIH risk classification. There were no extremely low- or low-risk groups (Table II).

Treatment outcomes. Sorafenib was administered to 25 patients and all patients were followed up after the administration at regular intervals until mortality or the time this manuscript 
Table I. Patient characteristics.

\begin{tabular}{|c|c|}
\hline Characteristics & Value \\
\hline \multicolumn{2}{|l|}{ Age, years } \\
\hline Median (range) & $54.0(16-82)$ \\
\hline \multicolumn{2}{|l|}{ Gender, n (\%) } \\
\hline Male & $17(68.0)$ \\
\hline Female & $8(32.0)$ \\
\hline \multicolumn{2}{|l|}{ Tumor site, n (\%) } \\
\hline Stomach & $6(24.0)$ \\
\hline Small intestine & $16(64.0)$ \\
\hline Colon & $1(4.0)$ \\
\hline Other sites & $2(8.0)$ \\
\hline \multicolumn{2}{|c|}{ Histopathology, n (\%) } \\
\hline Spindle cell type & $9(36.0)$ \\
\hline Epitheloid & $7(28.0)$ \\
\hline Mixed type & $9(36.0)$ \\
\hline \multicolumn{2}{|c|}{ Cd117 positivity, n (\%) } \\
\hline $\mathrm{Cd} 117^{+}, \mathrm{Cd} 34^{+}$ & $17(68.0)$ \\
\hline $\mathrm{Cd} 117^{+}, \mathrm{Cd} 34^{-}$ & $8(32.0)$ \\
\hline \multicolumn{2}{|c|}{ Site of metastases, n (\%) } \\
\hline Liver & $11(64.7)$ \\
\hline Peritoneum & $3(17.6)$ \\
\hline Lung & $1(5.9)$ \\
\hline Others & $2(11.8)$ \\
\hline \multicolumn{2}{|c|}{ Duration of imatinib usage, n (\%) } \\
\hline$<6$ months & $4(16.0)$ \\
\hline$>6$ months & $21(84.0)$ \\
\hline
\end{tabular}

was written. The dosage of sorafenib was 2 x $400 \mathrm{mg} /$ day at the beginning of the treatment. Treatment was continued until the patient no longer clinically benefitted from therapy or until unacceptable toxicity occurred. Temporary dose interruption and/or dose reduction of sorafenib therapy was provided if an intolerance or any adverse effects occurred.

A total of $18(72.0 \%)$ patients received $400 \mathrm{mg} /$ day imatinib and seven patients $(28.0 \%)$ with $\mathrm{PD}$ received $600-800 \mathrm{mg} /$ day imatinib in second-line treatment. All the patients had PD during imatinib treatment and no patients were intolerant to imatinib.

Of the patients, 12 received sorafenib in the third-line and 13 received it in the fourth-line treatment. Nine of the patients who received sorafenib in the fourth-line received sunitinib and three received nilotinib in the third-line treatment. Overall, $10(40 \%)$ of the patients achieved responses while receiving sorafenib. This represents the clinical benefit of sorafenib as determined by the sum of PR and SD. No patients achieved CR. Six patients $(24.0 \%)$ achieved PR and four $(16.0 \%)$ achieved SD during sorafenib usage. A total of $15(60 \%)$ patients showed PD at the time of analysis according to RECIST.

The median PFS and OS times of the patients that received sorafenib were 7.2 months (95\% CI, 5.47-8.92) and 15.2 months (95\% CI, 9.26-21.13), respectively (Figs. 1
Table II. Tumor characteristics of 25 patients with gastrointestinal stromal tumors receiving sorafenib treatment.

\begin{tabular}{lc}
\hline Variables & Number of patients $(\%)$ \\
\hline Tumor size, cm & \\
$2-5$ & $3(12.0)$ \\
$5-10$ & $4(16.0)$ \\
$>10$ & $18(72.0)$ \\
Mitosis, HPF & \\
$\leq 5 / 50$ & $8(32.0)$ \\
$>6-10 / 50$ & $5(20.0)$ \\
$>10 / 50$ & $12(48.0)$ \\
Fletcher risk categories & \\
Very low & $0(0.0)$ \\
Low & $0(0.0)$ \\
Intermediate & $6(24.0)$ \\
High & $19(76.0)$
\end{tabular}

HPF, high power field.

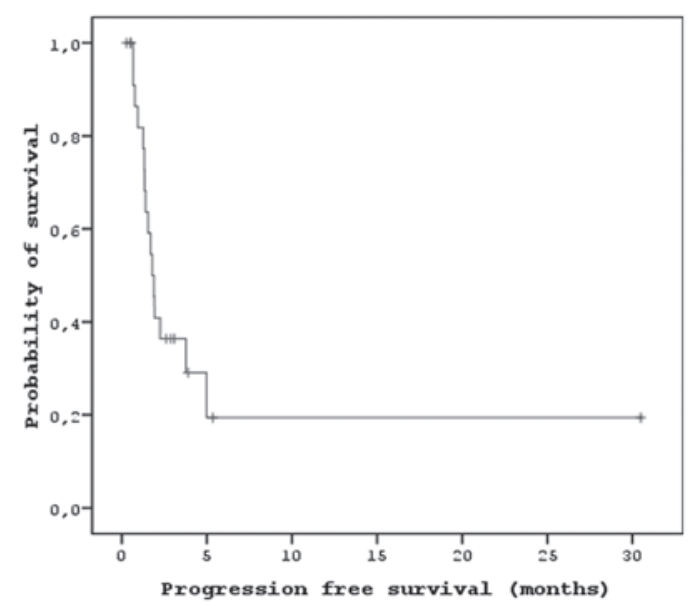

Figure 1. Progression-free survival (PFS) of the 25 patients that received sorafenib.

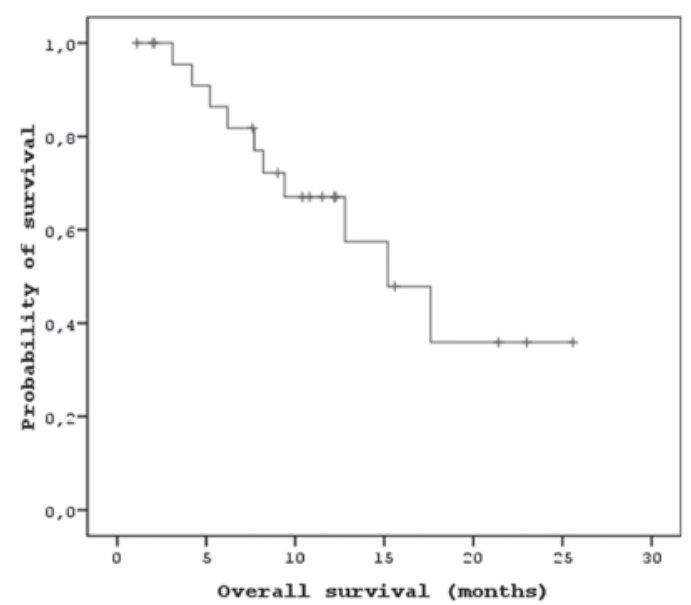

Figure 2. Overall survival (OS) of the 25 patients that received sorafenib. 
Table III. Univariate analysis between clinopathological characteristics of the patient group and OS and PFS

\begin{tabular}{|c|c|c|c|c|c|c|}
\hline \multirow[b]{2}{*}{ Variables } & \multicolumn{3}{|c|}{ PFS } & \multicolumn{3}{|c|}{ OS } \\
\hline & $\begin{array}{l}\text { Median } \\
\text { (months) }\end{array}$ & $\begin{array}{l}95 \% \text { CI } \\
\text { (months) }\end{array}$ & P-value & $\begin{array}{l}\text { Median } \\
\text { (months) }\end{array}$ & $\begin{array}{l}95 \% \text { CI } \\
\text { (months) }\end{array}$ & P-value \\
\hline Age, years & & & 0.052 & & & 0.482 \\
\hline$<50$ & 15.08 & $6.89-29.47$ & & 15.06 & $10.13-20.02$ & \\
\hline$>50$ & 6.94 & $2.43-8.00$ & & 15.32 & $7.84-22.31$ & \\
\hline Gender & & & 0.866 & & & 0.858 \\
\hline Men & 5.29 & $2.31-8.26$ & & 16.59 & $10.37-22.87$ & \\
\hline Women & 15.08 & $8.50-17.67$ & & 12.89 & $7.46-18.92$ & \\
\hline Tumor site & & & 0.008 & & & 0.223 \\
\hline Stomach & 15.08 & $9.56-17.32$ & & 17.18 & $8.83-25.52$ & \\
\hline Small intestine & 6.29 & $5.08-6.49$ & & 15.12 & $12.63-21.60$ & \\
\hline Colon & 2.73 & $2.43-2.83$ & & 10.15 & $10.15-10.15$ & \\
\hline Other sites & 2.62 & NA & & 9.86 & NA & \\
\hline Histopathology & & & 0.499 & & & 0.179 \\
\hline Spindle cell type & 3.02 & $2.53-6.14$ & & 17.77 & NA & \\
\hline Epitheloid & 4.76 & NA & & 11.99 & NA & \\
\hline Mixed type & 15.08 & $8.14-30.35$ & & 19.37 & $15.93-22.80$ & \\
\hline Tumor size, cm & & & 0.709 & & & 0.811 \\
\hline $2-5$ & 4.76 & NA & & 11.99 & NA & \\
\hline $5-10$ & 5.22 & $2.66-8.25$ & & 10.58 & $3.94-18.81$ & \\
\hline$>10$ & 7.65 & $1.24-14.06$ & & 15.02 & $11.33-21.12$ & \\
\hline Mitotic count, HPF & & & 0.018 & & & 0.233 \\
\hline$\leq 5 / 50$ & 15.08 & $12.73-22.79$ & & 15.00 & $13.46-22.51$ & \\
\hline$>6-10 / 50$ & 4.76 & $2.44-7.17$ & & 11.99 & 7.19-14.08 & \\
\hline$>10 / 50$ & 2.43 & $1.05-6.66$ & & 6.59 & $3.44-11.16$ & \\
\hline Duration of imatinib usage, months & & & 0.018 & & & 0.003 \\
\hline$<6$ & 3.10 & $1.15-5.64$ & & 4.20 & $2.78-8.56$ & \\
\hline$>6$ & 7.60 & $3.85-11.34$ & & 17.60 & $12.78-23.68$ & \\
\hline Response to sorafenib & & & 0.000 & & & 0.007 \\
\hline PR-SD & 12.08 & $11.36-20.76$ & & 15.87 & $11.10-34.51$ & \\
\hline PD & 5.60 & $4.12-6.83$ & & 10.56 & $3.80-20.17$ & \\
\hline
\end{tabular}

PFS, progression-free survival; OS, overall survival; PR, partial response; SD, stable disease; PD, progressive disease; NA, not available; HPF, high power field.

Table IV. The multivariate analysis between clinopathological characteristics of the patient group and OS and PFS.

\begin{tabular}{lccccccc}
\hline & \multicolumn{3}{c}{ PFS } & & & \multicolumn{2}{c}{ OS } \\
\cline { 2 - 5 } \cline { 5 - 7 } Variables & Hazard ratio & $95 \%$ CI & P-value & & Hazard ratio & 95\% CI & P-value \\
\hline Duration of imatinib usage & 0.079 & $0.007-0.895$ & 0.04 & & 0.058 & $0.005-0.65$ & 0.021 \\
\hline
\end{tabular}

PFS, progression-free survival; OS, overall survival.

and 2). In the univariate analysis, there were significant correlations between localization $(\mathrm{P}<0.01)$ and PFS. There were also significant correlations between the duration of imatinib usage, the response to sorafenib and the PFS and OS
$(\mathrm{P}<0.05$; Figs. 3 and 4). There were no associations between age, gender, tumor risk category, imatinib dose, duration of sunitinib usage and PFS and OS $(\mathrm{P}>0.05)$. In the multivariate analysis, there were significant associations between 


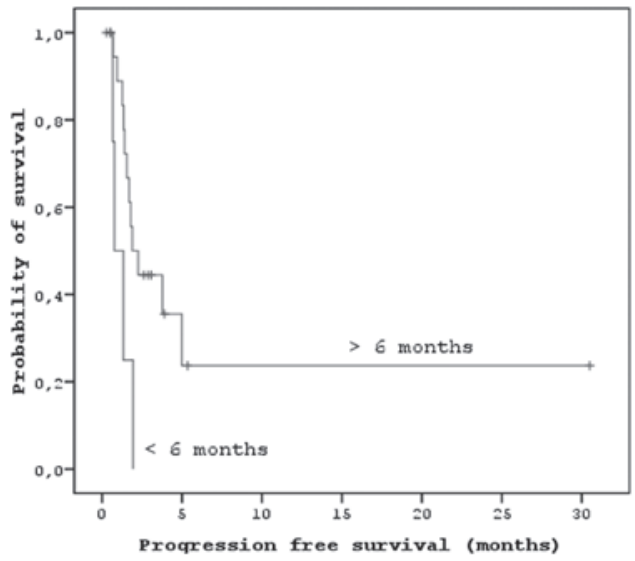

Figure 3. Univariate analysis between the duration of imatinib usage and progression-free survival (PFS). Patients received imatinib for either more or less than six months.

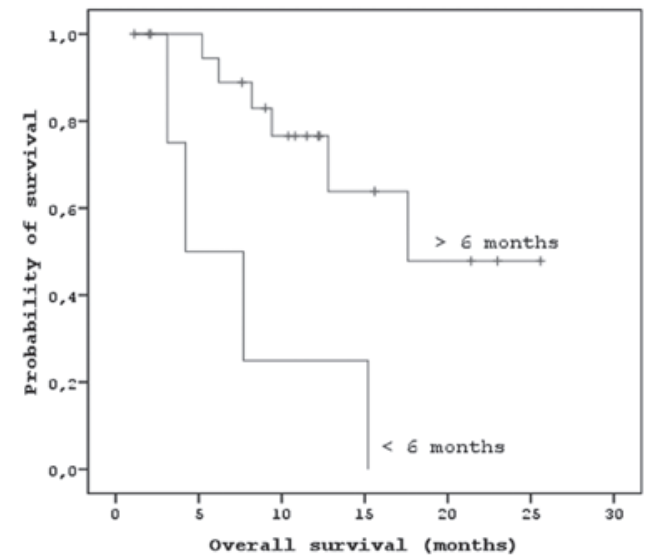

Figure 4. Univariate analysis between the duration of imatinib usage and overall survival. Patients received imatinib for either more or less than six months.

the duration of imatinib usage and PFS $(\mathrm{P}<0.05)$ and $\mathrm{OS}$ $(\mathrm{P}<0.05$; Tables III and IV).

Treatment-related adverse events were reported in $72 \%$ of the patients. These adverse events were generally mild to moderate in intensity and managed by dose reduction or standard supportive medical treatments. Hypertension only occurred in one patient and this was managed with anti-hypertensive drugs. None of the patients discontinued sorafenib treatment due to adverse events. The most common adverse events of any grade were skin rashes (54\%), thrombocytopenia (34\%) and fatigue (38\%). The most common grade III side-effect was hand-foot syndrome (HFS; 38\%); $41 \%$ of these patients received dose reductions due to HFS.

\section{Discussion}

Approximately 50\% of patients with GIST eventually develop progression within 24 months of imatinib treatment (33). Patients with advanced GIST who undergo disease progression or are intolerant to first-line imatinib therapy usually start second-line sunitinib malate therapy. As has been observed for imatinib in a first-line setting, the majority of patients showing an initial clinical benefit from sunitinib develop PD (34). In a prospective multicenter phase II study involving patients with unresectable, KIT-positive GIST that had progressed on treatment with imatinib and sunitinib, the median PFS and OS times were 5.2 and 11.6 months, respectively, while the one- and two-year survival rates were 50 and $29 \%$, respectively (27). In a retrospective analysis of 32 patients, sorafenib exhibited significant clinical activity in a heavily pretreated group of patients with metastatic GIST resistant to imatinib, sunitinib and nilotinib (28). In a more recent study, patients with metastatic GISTs refractory to first-line imatinib and second-line sunitinib were treated at the discretion of their physician. The authors concluded that sorafenib had significant clinical activity in imatinib-resistant and sunitinib-resistant GISTs (34). In the present study, as in these studies, in heavily pretreated patients, the median PFS and OS times of the patients that received sorafenib were 7.2 and 15.2 months, respectively. Thus, the present study demonstrated the improved effect of sorafenib in patients with metastatic GIST who experience previous treatment failure.

In the present study, the duration of imatinib usage significantly affected PFS and OS. Demetri et al detected no association between the duration of imatinib treatment and survival (7). In the present study, the majority of the patients treated with sunitinib used imatinib for $>12$ months. Of these patients, those who received imatinib for longer had improved OS and PFS times than those who received it for a shorter time. There were no significant associations between the dose of imatinib and OS and PFS $(\mathrm{P}>0.05)$.

The current risk-group stratification according to Fletcher et al does not include the possible effect of the tumor site (32). Another recently suggested GIST risk-group stratification system takes the tumor site into account, as well as tumor size and the mitotic rate, dividing GISTs into possibly benign, uncertain or low malignancy potential and possibly malignant (35). In the present study, the majority of patients were classified as high-risk (76.0\%) according to the NIH risk classification. This result was significantly higher than that reported by previous studies $(36,37)$. There were no associations between tumor size, mitosis, risk category and PFS and OS. These differences may be explained by the progressive nature of the GISTs in patients receiving sorafenib treatment and should be evaluated with further studies.

In the present study, the clinical benefit rate of sorafenib treatment was $40 \%$. This clinical benefit rate was lower than that in the phase II study reported by Kindler et al (27). Reichardt et al reported that $19 \%$ of patients who received sorafenib after the failure of imatinib, sunitinib and nilotinib in fourth-line treatment achieved partial remission, while $44 \%$ achieved disease stabilization (28). Based on the response rates achieved in the present study and these previous studies, sorafenib treatment may be accepted as clinically beneficial, although the limited experience with regard to response rates while using sorafenib treatment should be further evaluated with larger prospective series. Additionally, to determine the best practice in the third-line or fourth-line treatment, randomized, prospective comparative studies between sorafenib and other agents such as regorafenib should be conducted.

Italiano et al observed that albumin levels and KIT/PDGFRA mutational status were significantly associated 
with PFS, whereas performance status and albumin level were associated with OS (34). Furthermore, Heinrich et al indicated that sorafenib was more effective than imatinib or sunitinib for inhibiting the kinase activity of drug-resistant KIT mutants (26). As a limitation to the present study we were unable to determine the kinase mutations in our patients. In Turkey, it is not a routine practice to determine kinase mutations. Kinase mutations may explain the differences in the longevity of the PFS and OS and lower response rates in the present study. Therefore, an analysis of these mutations should be performed in further studies.

Sorafenib treatment is associated with several adverse effects. Fatigue, skin rashes and hematological toxicity were the most common side-effects in the present study. These side-effects are generally mild and may be managed by dose modulation. The toxicity profile reported in the present study was similar to that observed in previous studies, with the exception of hypertension $(27,38)$. No serious treatment-related hypertension was observed with sorafenib and there was no treatment discontinuation.

In summary, sorafenib is an active and effective agent with a reasonable side-effect profile in the treatment of patients with gastrointestinal stromal tumors in third- or fourth-line treatments that are refractory to previous therapies. A significant number of patients with advanced GIST benefitted from sorafenib, with OS times exceeding one year. It was observed that the duration of imatinib usage was a significant independent prognostic factor for PFS and OS. Future prospective studies of sorafenib in GIST should investigate these factors to clarify the correlations of this clinical benefit.

\section{Acknowledgements}

The authors would like to thank the patients and advocates who supported the present study and the teams of research nurses and study coordinators at all centres who made this work possible.

\section{References}

1. Rubin BP, Heinrich MC and Corless CL: Gastrointestinal stromal tumour. Lancet 369: 1731-1741, 2007.

2. Miettinen M and Lasota J: Gastrointestinal stromal tumors: review on morphology, molecular pathology, prognosis, and differential diagnosis. Arch Pathol Lab Med 130: 1466-1478, 2006.

3. Hirota S, Isozaki K, Moriyama Y, et al: Gain-of-function mutations of c-kit in human gastrointestinal stromal tumors. Science 279: 577-580, 1998.

4. Heinrich MC, Corless CL, Demetri GD, et al: Kinase mutations and imatinib response in patients with metastatic gastrointestinal stromal tumor. J Clin Oncol 21: 4342-4349, 2003.

5. Heinrich MC, Corless CL, Duensing A, et al: PDGFRA activating mutations in gastrointestinal stromal tumors. Science 299: 708-710, 2003.

6. Tran T, Davila JA and El-Serag HB: The epidemiology of malignant gastrointestinal stromal tumors: an analysis of 1,458 cases from 1992 to 2000. Am J Gastroenterol 100: 162-168, 2005.

7. Demetri GD, von Mehren M, Blanke CD, et al: Efficacy and safety of imatinib mesylate in advanced gastrointestinal stromal tumors. N Engl J Med 347: 472-480, 2002.

8. Akwari OE, Dozois RR, Weiland LH and Beahrs OH: Leiomyosarcoma of the small and large bowel. Cancer 42: 1375-1384, 1978.

9. Shiu MH, Farr GH, Papachristou DN and Hajdu SI: Myosarcomas of the stomach: natural history, prognostic factors and management. Cancer 49: 177-187, 1982.

10. McGrath PC, Neifeld JP, Lawrence W Jr, Kay S, Horsley JS 3rd and Parker GA: Gastrointestinal sarcomas. Analysis of prognostic factors. Ann Surg 206: 706-710, 1987.
11. Ng EH, Pollock RE, Munsell MF, Atkinson EN and Romsdahl MM: Prognostic factors influencing survival in gastrointestinal leiomyosarcomas. Implications for surgical management and staging. Ann Surg 215: 68-77, 1992.

12. Druker BJ, Tamura S, Buchdunger E, et al: Effects of a selective inhibitor of the Abl tyrosine kinase on the growth of Bcr-Abl positive cells. Nat Med 2: 561-566, 1996.

13. Buchdunger $\mathrm{E}$, Cioffi CL, Law N, et al: Abl protein-tyrosine kinase inhibitor STI571 inhibits in vitro signal transduction mediated by c-kit and platelet-derived growth factor receptors. J Pharmacol Exp Ther 295: 139-145, 2000.

14. Heinrich MC, Griffith DJ, Druker BJ, Wait CL, Ott KA and Zigler AJ: Inhibition of c-kit receptor tyrosine kinase activity by STI 571, a selective tyrosine kinase inhibitor. Blood 96: 925-932, 2000.

15. Wang WL, Healy ME, Sattler M, et al: Growth inhibition and modulation of kinase pathways of small cell lung cancer cell lines by the novel tyrosine kinase inhibitor STI 571 . Oncogene 19: 3521-3528, 2000.

16. Yeh CN, Chen TW, Wu TJ, Hsueh S and Jan YY: Treatment of patients with advanced gastrointestinal stromal tumor of small bowel: implications of imatinib mesylate. World $J$ Gastroenterol 12: 3760-3765, 2006.

17. Yeh CN, Chen TW, Lee HL, et al: Kinase mutations and imatinib mesylate response for 64 Taiwanese with advanced GIST: preliminary experience from Chang Gung Memorial Hospital. Ann Surg Oncol 14: 1123-1128, 2007.

18. Chen YY, Yeh CN, Cheng CT, et al: Sunitinib for Taiwanese patients with gastrointestinal stromal tumor after imatinib treatment failure or intolerance. World J Gastroenterol 17: 2113-2119, 2011.

19. Rutkowski P, Debiec-Rychter M and Ruka W: Gastrointestinal stromal tumors: key to diagnosis and choice of therapy. Mol Diagn Ther 12: 131-143, 2008.

20. Osusky KL, Hallahan DE, Fu A, et al: The receptor tyrosine kinase inhibitor SU11248 impedes endothelial cell migration, tubule formation, and blood vessel formation in vivo, but has little effect on existing tumor vessels. Angiogenesis 7: 225-233, 2004.

21. Abrams TJ, Lee LB, Murray LJ, Pryer NK and Cherrington JM: SU11248 inhibits KIT and platelet-derived growth factor receptor beta in preclinical models of human small cell lung cancer. Mol Cancer Ther 2: 471-478, 2003.

22. Mendel DB, Laird AD, Xin X, et al: In vivo antitumor activity of SU11248, a novel tyrosine kinase inhibitor targeting vascular endothelial growth factor and platelet-derived growth factor receptors: determination of a pharmacokinetic/pharmacodynamic relationship. Clin Cancer Res 9: 327-337, 2003.

23. Murray LJ, Abrams TJ, Long KR, et al: SU11248 inhibits tumor growth and CSF-1R-dependent osteolysis in an experimental breast cancer bone metastasis model. Clin Exp Metastasis 20: 757-766, 2003

24. O'Farrell AM, Abrams TJ, Yuen HA, et al: SU11248 is a novel FLT3 tyrosine kinase inhibitor with potent activity in vitro and in vivo. Blood 101: 3597-3605, 2003.

25. Schueneman AJ, Himmelfarb E, Geng L, et al: SU11248 maintenance therapy prevents tumor regrowth after fractionated irradiation of murine tumor models. Cancer Res 63: 4009-4016, 2003.

26. Heinrich MC, Marino-Enriquez A, Presnell A, et al: Sorafenib inhibits many kinase mutations associated with drug-resistant gastrointestinal stromal tumors. Mol Cancer Ther 11: 1770-1780, 2012.

27. Kindler HL, Campbell NP, Wroblewski K, et al: Sorafenib (SOR) in patients (pts) with imatinib (IM) and sunitinib (SU)-resistant (RES) gastrointestinal stromal tumors (GIST): Final results of a University of Chicago Phase II Consortium trial. J Clin Oncol (ASCO Meeting Proceedings) 29: 10009, 2011.

28. Reichardt $\mathrm{P}$, Montemurro $\mathrm{M}$, Gelderblom $\mathrm{H}$, et al: Sorafenib fourth-line treatment in imatinib-, sunitinib-, and nilotinib-resistant metastatic GIST: A retrospective analysis. J Clin Oncol (2009 ASCO Annual Meeting) 27 (15 Suppl): Abstract 10564, 2009.

29. National Comprehensive Cancer Network: NCCN Clinical Practice Guidelines in Oncology (NCCN Guidelines): Soft Tissue Sarcoma. Version 2.2012. www.NCCN.org. Accessed June 17, 2012.

30. Eisenhauer EA, Therasse P, Bogaerts J, et al: New response evaluation criteria in solid tumours: revised RECIST guideline (version 1.1). Eur J Cancer 45: 228-247, 2009. 
31. Miettinen M and Lasota J: Gastrointestinal stromal tumors - definition, clinical, histological, immunohistochemical, and molecular genetic features and differential diagnosis. Virchows Arch 438: 1-12, 2001.

32. Fletcher CD, Berman JJ, Corless C, et al: Diagnosis of gastrointestinal stromal tumors: A consensus approach. Hum Pathol 33: 459-465, 2002.

33. Verweij J, Casali PG, Zalcberg J, et al: Progression-free survival in gastrointestinal stromal tumours with high-dose imatinib: randomised trial. Lancet 364: 1127-1134, 2004.

34. Italiano A, Cioffi A, Coco P, et al: Patterns of care, prognosis, and survival in patients with metastatic gastrointestinal stromal tumors (GIST) refractory to first-line imatinib and second-line sunitinib. Ann Surg Oncol 19: 1551-1559, 2012.

35. Miettinen M, El-Rifai W, Sobin LH and Lasota J: Evaluation of malignancy and prognosis of gastrointestinal stromal tumors: a review. Hum Pathol 33: 478-483, 2002.
36. Nilsson B, Bümming $\mathrm{P}$, Meis-Kindblom JM, et al: Gastrointestinal stromal tumors: the incidence, prevalence, clinical course, and prognostication in the preimatinib mesylate era - a population-based study in western Sweden. Cancer 103: 821-829, 2005.

37. Cao H, Zhang Y, Wang M, et al: Prognostic analysis of patients with gastrointestinal stromal tumors: a single unit experience with surgical treatment of primary disease. Chin Med J (Engl) 123: 131-136, 2010.

38. Keohan M, D'Adamo D, Qin L, et al: Analysis of toxicity in a phase II study of sorafenib in soft tissue sarcoma (STS). J Clin Oncol 2007 ASCO Annual Meeting Proceedings (Post-Meeting Edition) 25 (18 Suppl): 10061, 2007. 